\title{
CHARACTERISATION OF THE NUCLEIC ACID BINDING FEATURES OF THE PRRSV 7ap AND ITS ABILITY TO INDUCE ANTINUCLEAR ANTIBODIES
}

\author{
Ferenc OlAsZ ${ }^{1}$, Béla DÉnes ${ }^{2}$, Ádám BÁLINT $^{2}$, Tibor MAGYAR $^{1}$, Sándor BELÁK ${ }^{3}$ \\ and Zoltán ZÁDORI ${ }^{1 *}$
}

${ }^{1}$ Institute for Veterinary Medical Research, Centre for Agricultural Research, Hungarian Academy of Sciences, Hungária krt. 21, H-1143 Budapest, Hungary; ${ }^{2}$ Veterinary Diagnostic Directorate National Food Chain Safety Office, Budapest, Hungary;

${ }^{3}$ Department of Biomedical Sciences and Veterinary Public Health (BVF), Swedish University of Agricultural Sciences (SLU), Uppsala, Sweden

(Received 21 July 2016; accepted 2 November 2016)

A short alternative open reading frame named ORF7a has recently been discovered within the nucleocapsid gene of the porcine reproductive and respiratory syndrome virus (PRRSV) genome. Proteins (7ap) translated from the ORF7a of two divergent strains - a type I and a type II - are able to completely reduce the motility of nucleic acids at relatively high molar charge ratios in gel retardation assays indicating strong dsDNA- and ssRNA-binding capability. Conserved RNAand DNA-binding properties suggest that nucleic acid binding is a functional property of the divergent 7aps, and not an arbitrary consequence of their net positive charge. Sera from Hu7ap-immunised pigs and mice did not react with Hu7ap or Hu7ap-GFP; however, antinuclear antibodies were detected in the sera of the immunised animals, suggesting an ability of Hu7ap to interact with or mimic autoantigenic macromolecules.

Key words: Porcine reproductive and respiratory syndrome virus, ORF7a, 7 ap proteins, nucleic acid binding features, antinuclear antibodies

The porcine reproductive and respiratory syndrome virus (PRRSV) belongs to the Arteriviridae family of the Nidovirales order. Since its appearance in the late 1980s, PRRSV has caused substantial economic losses to the global swine industry (Osorio, 2010; Duinhof, 2011; Zhang and Kono, 2012; Holtkamp et al., 2013). PRRSV has a high mutation rate, which led to the evolution of two major genotypes: type 1 or European, and type 2 or North American (Murtaugh et al., 2010). The high genetic diversity of PRRSV hinders efforts to produce vaccines that are cross-protective to heterogeneous PRRSV strains (Mateu and Diaz, 2008; Balka et al., 2016). The size of the PRRSV genome is around 15,000 bases that contains eight larger open reading frames (ORFs). A large polyprotein

\footnotetext{
*Corresponding author; E-mail: zadori.zoltan@agrar.mta.hu
} 
is translated from the first two ORFs by ribosomal frameshift. Proteolytic digestion of the polyprotein resulted in at least 16 non-structural proteins that are involved in the viral RNA replication. The remaining six ORFs encode the structural proteins. Overlapping with ORF 1a, ORF 2 and ORF 5 three other smaller ORFs were identified, from which three accessory proteins are translated by noncanonical translation mechanisms (Snijder and Meulenberg, 1998; Meulenberg, 2000; Wu et al., 2001; Firth et al., 2011; Fang et al., 2012; Olasz et al., 2016a).

In a previous paper we reported the presence of a short alternative open reading frame named ORF7a in the genome of various PRRSV strains. ORF7a overlaps with the coding region of the $\mathrm{N}$ gene (Olasz et al., 2016b). Depending on the virus strain, the length of the encoded protein (7ap) is between 36 and 53 amino acids (aa). 7aps of two divergent PRRSV strains bind strongly to the Fc part of different mammalian IgGs. Furthermore, the 7ap of a type 1 strain (Hu7ap) inhibits complement fixation in vitro.

Here we investigate the DNA- and RNA-binding capacity of the 7ap of two divergent PRRSV strains, and describe the presence of antinuclear antibodies in sera from Hu7ap-immunised pigs and mice. The potential functional implications of the findings are discussed.

\section{Materials and methods}

Peptide synthesis

As we reported earlier (Olasz et al., 2016b), the 7aps of a type I (HU-14432/ 2011) (Hu7ap MTSGTTSPRLNAPSACNRSRRLSIKAQELRRFHPAGRSVFR LSLCCRLLIQCA) and a type II (WuH4) (Wu7ap MTSGITLPLVSGNCVCRRS RLPSIRVLELVPCQIQGG) strain were synthesised and purified to $95 \%$ purity by CASLO ApS (Lyngby, Denmark).

\section{$D N A$ and RNA gel retardation assay}

Nucleic acid probes were selected randomly by accessibility. The RNA probe was transcribed from the 14532-14889 fragment of the PRRSV SD01-08 strain cloned into the pcDNA3 vector. The plasmid was linearised with XbaI, and RNA was synthesised by the TranscriptAid T7 High Yield Transcription Kit (Thermo Scientific, Waltham, Massachusetts) following the manufacturer's recommendation. RNA was DNAse treated and purified with High Pure Viral Nucleic Acid Kit (Roche, Basel, Switzerland).

The double-stranded DNA sample was prepared from the pIRES-AcGFP1 plasmid by digestion with PvuII and HindIII. The PRRS3END (GGCAGGAAC CATGTGACCGAAATTAAAAAAAAAAAAAAAAAAAAAAAAGGGTCGGC ATGGC) oligonucleotide primer was used as single-stranded DNA probe. 
For the ssDNA-protein assay 7aps were incubated with $200 \mathrm{ng}$ PRR S3END in $7 \mu 14 \mathrm{mM} \mathrm{MgCl}_{2} 0.5 \mathrm{TE}(\mathrm{pH}$ 8). For the dsDNA-protein assay 7aps were incubated with $500 \mathrm{ng}$ digested pIRES-AcGFP1 in $7 \mu 14 \mathrm{mM} \mathrm{MgCl}_{2}$ $0.5 \mathrm{TE}(\mathrm{pH} 8)$. For the ssRNA-protein assay 7 aps were incubated with $1.3 \mu \mathrm{g}$ RNA and 2U RiboLock RNAse Inhibitor (Thermo Scientific, Waltham, Massachusetts) in $8 \mu 15 \mathrm{mM}$ Tris- $\mathrm{HCl}(\mathrm{pH} 8)$. All reaction mixtures were incubated at room temperature for $45 \mathrm{~min}$, then $4 \mu 1$ loading buffer $(25 \mathrm{mM}$ Tris- $\mathrm{HCl} \mathrm{pH} 8$ and $25 \%$ glycerol) was added, and the samples were loaded onto a $6 \%$ nondenaturing polyacrylamide gel casted by the Ornstein-Davis method (Ornstein and Davis, 1964) and run at $110 \mathrm{~V}$ in Tris-Glycine running buffer. Nucleic acids were visualised with GelRed Nucleic Acid Gel Stain (Biotium, Hayward, California) following the manufacturer's recommendation.

\section{Animal immunisation}

Two mice were immunised intramuscularly with a double dose of $0.2 \mathrm{ml}$ emulsion containing crashed gel slices with approximately $20 \mu \mathrm{g}$ HU7ap $(70 \mu \mathrm{l})$, paraffin oil and thiomersal-containing adjuvant $(130 \mu \mathrm{l})$ (Merial, Lyon, France). The two injections were separated by a two-week interval. A similar immunisation regime was executed with the K1p peptide (MEVYHFQMQIVLPWPAIH SGPCPSRRKCCRSPFNLSVW), which is a hypothetical peptide; its coding sequence overlaps with that of the M protein in the PRRSV genome. The K1pinjected mice served as negative controls in this experiment.

Two 3-month-old pigs were obtained from a PRRSV-free herd. One pig was immunised with a double dose of $0.5 \mathrm{ml}$ emulsion containing crashed gel slices with approximately $20 \mu \mathrm{g}$ HU7ap $(160 \mu \mathrm{l})$, paraffin oil and thiomersalcontaining adjuvant $(340 \mu \mathrm{l})$ (Merial, Lyon, France). The two injections were separated by an interval of 17 days. The other 3-month-old pig was immunised with a double dose of $0.5 \mathrm{ml}$ solution containing crashed gel slices with approximately $20 \mu \mathrm{g}$ HU7ap $(250 \mu \mathrm{l})$ and incomplete Freund's adjuvant $(250 \mu \mathrm{l})$. The two injections were separated by an interval of 17 days. All animals were sacrificed three weeks after the second injection. The animal experiments were specifically approved by the ethics committee of the Institute for Veterinary Medical Research, Centre for Agricultural Research, Hungarian Academy of Sciences. The animal experiment permits were issued by the Food Chain Safety and Animal Health Directorate of the Budapest and Pest County Agricultural Office (mouse immunisation permit number: 22.1/1041/3/2010, pig immunisation permit number: XIV-I-001/1300-4/2012).

\section{Expression of the Hu7ap fusion construct in Marc 145 cells}

7ap of the HU-14432/2011 strain was cloned into the p-MeGFPN1 plasmid as described earlier (Olasz et al., 2016b). The resulted plasmid expressing 
the Hu7ap-GFP fusion protein under the control of the CMV promoter was transfected into 24-well plated Marc 145 cells using the Turbofect (Thermo Scientific, Waltham, Massachusetts) transfection reagent following the manufacturer's recommendation.

\section{Indirect immunofluorescence (IF)}

After fixing the cells with $300 \mu 13 \%$ formaldehyde, they were washed twice with $1 \mathrm{ml}$ washing buffer [phosphate-buffered saline (PBS) and $0.1 \%$ Tween 20]. The samples were permeabilised with $200 \mu 11 \%$ Triton-X (in PBS) for $15 \mathrm{~min}$ at room temperature. Following two washing steps the fixed cells were incubated with $200 \mu \mathrm{l}$ serially diluted mouse and pig sera from the peptideimmunised animals in IF buffer (4\% horse serum in PBS) for $1 \mathrm{~h}$. The samples were washed twice, and $200 \mu \mathrm{l}$ of secondary antibodies [CF594 goat anti-mouse and CF568 goat anti-swine IgGs (Biotium Hayward, California) in 1000-fold dilution] and Hoechst 33342 reagent $(1 \mu \mathrm{g} / \mu \mathrm{l})$ were added. After $1 \mathrm{~h}$ incubation and two washings, the samples were examined under a Zeiss Axio Observer D1 inverse fluorescence research microscope.

\section{Results}

\section{Nucleic acid binding}

As we reported earlier, efforts to overexpress the Hu7ap in bacterial cells were unsuccessful, despite several attempts with two Escherichia coli expression systems. The cause of the failure of overexpression was that the Hu7ap protein proved to be highly toxic to the bacterial cells (Olasz et al., 2016b).

The external addition of the synthesised Hu7ap to bacterial culture or to eukaryotic cells did not inhibit bacterial or eukaryotic cell growth (data not shown). These observations lessened the possibility of membrane perturbation as a cause of toxicity, and raised the suspicion that nucleic acid interaction can be behind the lethal effect of Hu7ap expression in bacterial cells. 7aps contain several arginines and have a net positive charge that is the hallmark of nucleic acid binding proteins. DNA- or RNA-binding by the expressed 7ap can interfere with normal cellular processes, which might lead to bacterial toxicity. In line with this hypothesis, the RNA- and DNA-binding characteristics of two 7aps were investigated.

In a gel retardation assay $250 \mathrm{ng} \mathrm{Hu}$ ap was enough to prevent the entry of $0.5 \mu \mathrm{g}$ dsDNA into the gel, $5 \mu \mathrm{g}$ Hu7ap blocked the migration of $1.3 \mu \mathrm{g}$ ssRNA, and $200 \mathrm{ng}$ ssDNA was prevented from running into the gel by $1 \mu \mathrm{g} \mathrm{Hu} 7 \mathrm{ap}$. Similar results were achieved with $\mathrm{Wu} 7 \mathrm{ap}$, though the affinity of the peptides to the nucleic acids investigated was somewhat less $(8 \mu \mathrm{g}, 1 \mu \mathrm{g}$ and $10 \mu \mathrm{g}$ of Wu7ap 


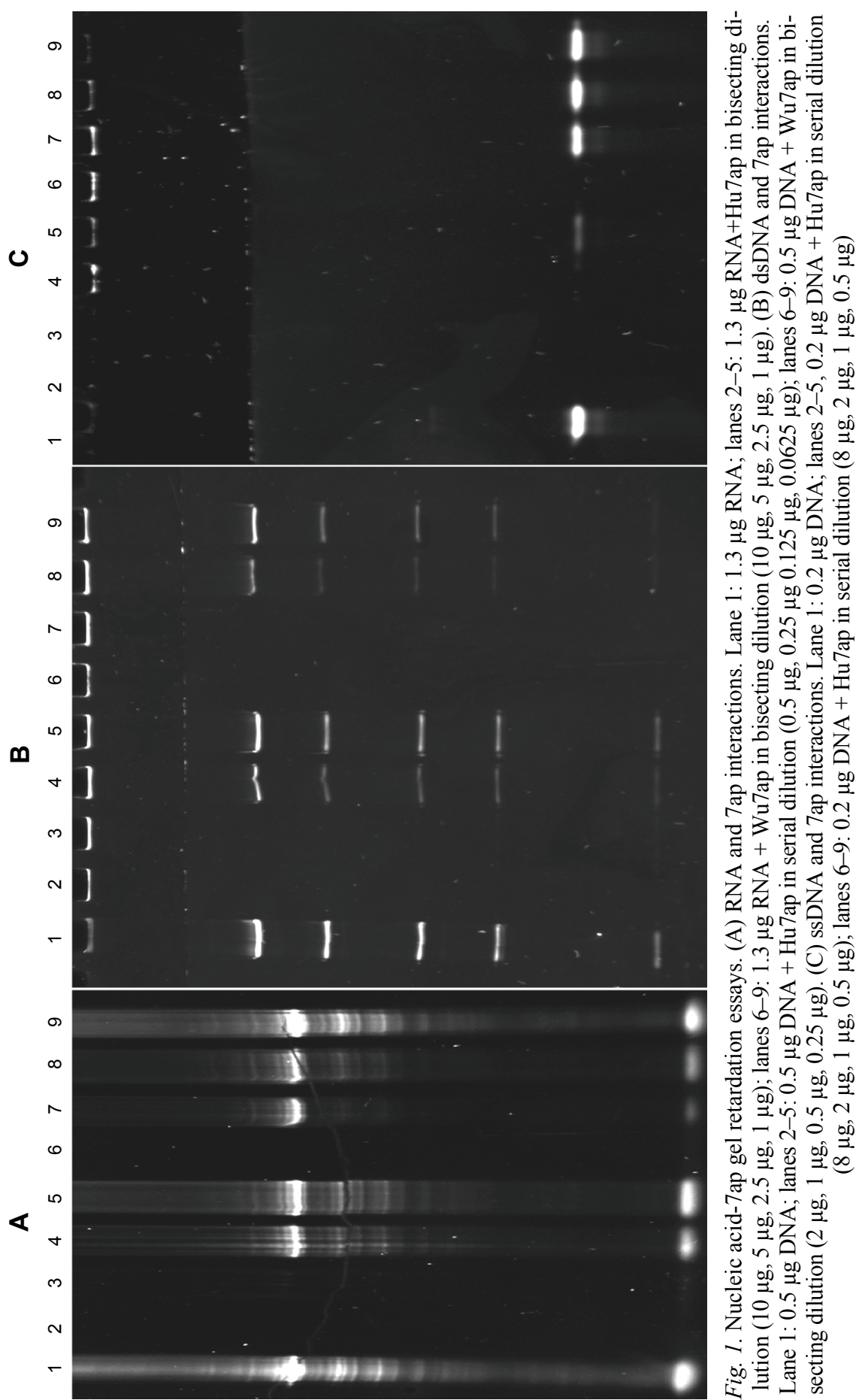




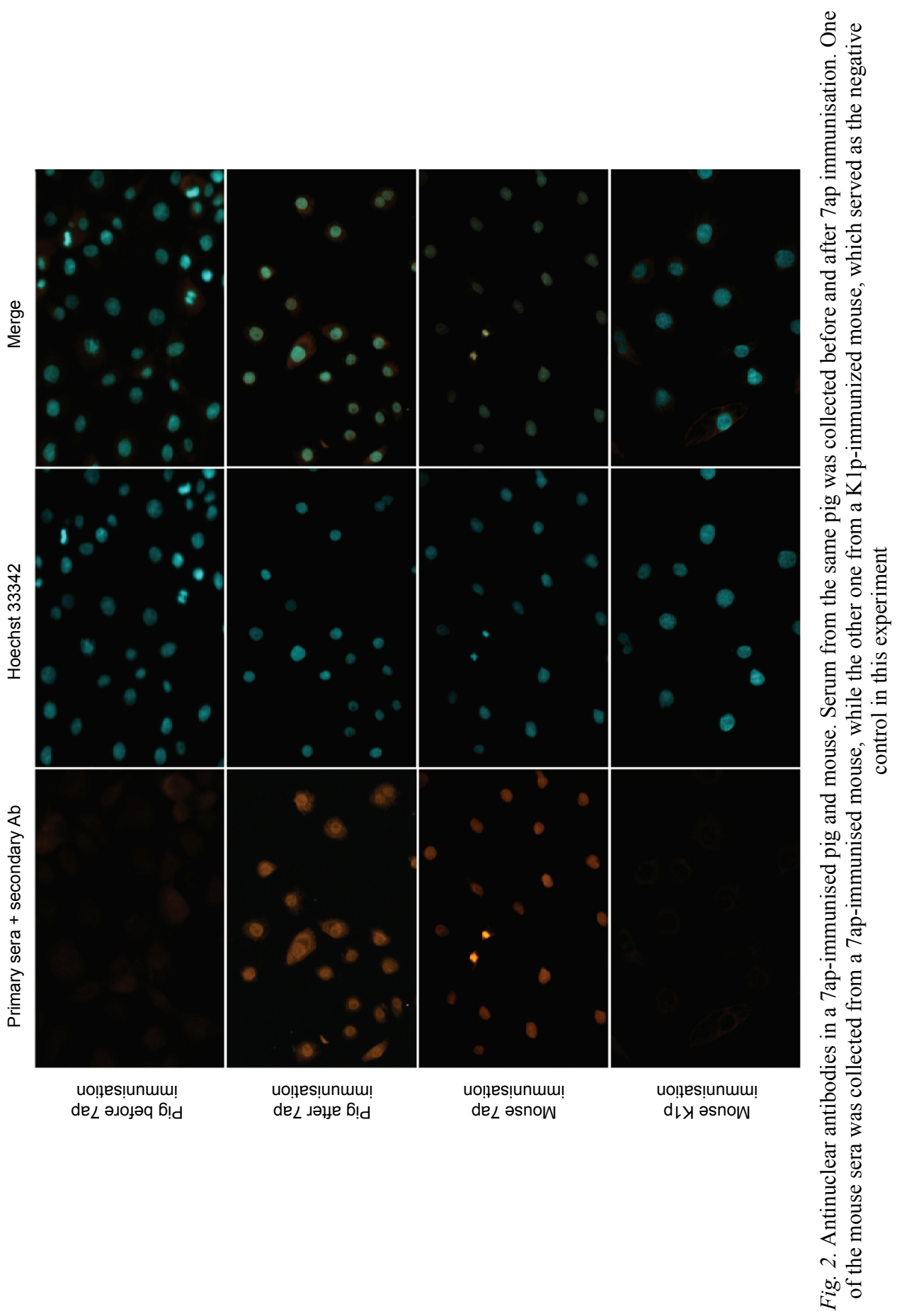


titrated out $200 \mathrm{ng}$ ssDNA, $0.5 \mu \mathrm{g}$ dsDNA and $1.3 \mu \mathrm{g}$ ssRNA, respectively) than that of the Hu7ap (Fig. 1). The molar charge ratios (total negative charge of the nucleic acids per total positive charge of the peptides in a reaction), where electrophoretic mobility of the nucleic acids is completely reduced (Hu7ap: $3.65>$ $0.5>0.34$, Wu7ap: $1.5>0.37>0.07$ for dsDNA, ssRNA and ssDNA, respectively) clearly indicate that both 7aps have the highest affinity to dsDNA while they bind ssDNA the least.

\section{Induction of antinuclear antibodies}

To further investigate the role of 7ap in the life cycle of PPRSV we intended to raise antibodies against Hu7ap. Two mice and two pigs were immunised with SDS-PAGE slices containing the peptide. However, no significant differences were detected against Hu7ap in ELISA between the sera of Hu7apimmunised animals and those of non-immunised animals (data not shown). To further investigate the reactivity of the sera they were examined in indirect IF on Hu7ap-GFP fusion protein transiently expressing Marc 145 cells. None of the immunised animals' sera reacted with Hu7ap-GFP (data not shown). However, antinuclear antibodies (ANA) were detected in the sera of all animals immunised with $\mathrm{Hu}$ 7ap (Fig. 2). The pig immunised with the incomplete Freund's adjuvant developed less ANA than the pig immunised with paraffin oil and thiomersal adjuvant as the antinuclear reactivity of the sera $(40 \times$ versus $200 \times$ dilution) indicated it in IF experiments. A high ANA titre was also revealed in both mice $(200 \times)$ immunised with Hu7ap. The emergence of ANA seemed to be specific to Hu 7ap because mice immunised with K1p by the same method did not develop nucleus-reactive antibodies (Fig. 2).

Interestingly, the sera of the two animal species reacted differently with the nucleus of the Marc 145 cells. Mouse sera reacted strongly with the chromosomes of mitotic cells indicating the presence of dsDNA-binding antibodies, whereas the sera of pigs showed a distinct fine-speckled staining with resting cells, and did not react with the chromosomes of dividing cells, which may indicate antibodies against RNA-binding nucleoproteins Ro and La (Buchner et al., 2014).

\section{Discussion}

The experiments presented here proved that in addition to its IgG binding capability (Olasz et al., 2016b), 7ap also has the potential to interact with nucleic acids. Several highly positively charged peptides and proteins are unable to bind to nucleic acids (Bousarghin et al., 2003), yet the two investigated 7aps relatively strongly bind to dsDNA and ssRNA. High sequential divergence and conserved RNA- and DNA-binding properties make it highly plausible that nucleic acid binding is functional, and it is not just an arbitrary consequence of the net posi- 
tive charge of 7aps. Functionality of the nucleic acid binding is further supported by the fact that highly positively charged HPV peptides with significantly lower DNA-binding affinity were able to protect DNA from DNase degradation, and were sufficient to obtain gene transfer in COS-7 cells (Bousarghin et al., 2003).

During transient expression 7ap is initially localised in the nucleus, and later accumulates in the cytoplasm (Olasz et al., 2016b). This localisation suggests multiple functions for the protein. One of the functions in the nucleus might be the perturbation of the normal host mRNA transcription and processing in cooperation with the viral nucleocapsid protein which is also positively charged and present in the nucleus (You et al., 2008). The cytoplasmic form of 7ap can interact with cellular RNAs and may influence normal translational processes of the host cells for the benefit of the virus. The interaction of 7ap with intracellular proteins is also a possibility. It was reported that the similarly short and basic HIV-1 Tat protein exerts its regulatory effect through both nucleic acid and protein interactions (Vitagliano et al., 2011). Immunisation of different species with Hu7ap failed to induce detectable antibodies against the protein. However, unsuccessful immunisation is not unusual with small viral proteins and peptides (Betakova et al., 2000; Celis, 2002; Zádori et al., 2005). More interestingly, despite the species, adjuvant and immunisation regime differences, all of the animals developed ANAs after immunisation with Hu7ap. These immunisation experiments suggest an ability of Hu7ap to interact with or mimic autoantigenic macromolecules and to induce the breakdown of self-tolerance in different animals. Autoantibodies directed against nuclear proteins during PRRSV infection were also reported (Lemke et al., 2004), so it is tempting to speculate that 7ap induces, or at least contributes to, this phenomenon. It is shown that several positively charged viral and bacterial peptides and proteins (Quaratino et al., 1995; Wucherpfennig and Strominger, 1995; Hausmann et al., 1999) can mimic sequentially unrelated positively charged autoantigens of human proteins (e.g. myelin basic protein, proteins of ribonucleoprotein complex Ro/La, C1q) (Routsias and Tzioufas, 2010; Stoyanova et al., 2012; Mameli et al., 2014), and can activate autoreactive T and B cell responses (Vaughan et al., 1995; Wucherpfennig and Strominger, 1995; Sospedra et al., 2005). However, sometimes, just like in the case of nuclear antigens and Hu7ap, cross-reactivity between autoantigens and the inducer of the autoantibodies cannot be detected (Vaughan et al., 1995).

One possible explanation can be that 7ap itself is not immunogenic, but binds to DNA or nucleoprotein complexes released during and after injection from damaged tissue (mechanical injury- and adjuvant-generated necrosis or inflammation-induced apoptosis), and it may interfere with the normal DNA clearance processes mediated by serum amyloid $\mathrm{P}$ and $\mathrm{C}$-reactive protein binding (Mold et al., 2001). Normally DNA and nucleoproteins are rapidly cleared from an injury site, and failure of clearance can lead to DNA or nucleoprotein specific B cell activation (Du Clos, 1996; Bickerstaff et al., 1999). 
In the present paper we revealed two novel biologically relevant characteristics of the 7ap protein of PRRSV. The protein binds nucleic acid and during immunisation it is able to induce ANA. Further investigations are needed to clarify the in vivo significance of these features in the life cycle of PRRSV.

\section{Acknowledgements}

This paper was supported by the János Bolyai Research Scholarship and by the Hungarian Scientific Research Fund (OTKA) fund (OTKA K-108607).

\section{References}

Balka, Gy., Dreckmann, K., Papp, Gy. and Kraft, C. (2016): Vaccination of piglets at 2 and 3 weeks of age with Ingelvac PRRSFLEX ${ }^{\mathbb{B}}$ EU provides protection against heterologous field challenge in the face of homologous maternally derived antibodies. Porcine Health Management 2, 24. DOI: 10.1186/s40813-016-0037-y.

Betakova, T., Wolffe, E. J. and Moss, B. (2000): The vaccinia virus A14.5L gene encodes a hydrophobic 53-amino-acid virion membrane protein that enhances virulence in mice and is conserved among vertebrate poxviruses. J. Virol. 74, 4085-4092.

Bickerstaff, M. C., Botto, M., Hutchinson, W. L., Herbert, J., Tennent, G. A., Bybee, A., Mitchell, D. A., Cook, H. T., Butler, P. J., Walport, M. J. and Pepys, M. B. (1999): Serum amyloid P component controls chromatin degradation and prevents antinuclear autoimmunity. Nat. Med. 5, 694-697.

Bousarghin, L., Touzé, A., Combita-Rojas, A. L. and Coursaget, P. (2003): Positively charged sequences of human papillomavirus type 16 capsid proteins are sufficient to mediate gene transfer into target cells via the heparan sulfate receptor. J. Gen. Virol. 84, 157-164.

Buchner, C., Bryant, C., Eslami, A. and Lakos, G. (2014): Anti-nuclear antibody screening using HEp-2 cells. J. Vis. Exp. 88, e51211. DOI: 10.3791/51211.

Celis, E. (2002): Getting peptide vaccines to work: just a matter of quality control? J. Clin. Invest. 110, $1765-1768$.

Du Clos, T. W. (1996): The interaction of C-reactive protein and serum amyloid P component with nuclear antigens. Mol. Biol. Rep. 23, 253-260.

Duinhof, T. (2011): Economical impact of PRRSV outbreaks in sow herds. EuroPRRS2011 Lecture conducted from Animal Health Service, Deventer, The Netherlands.

Fang, Y., Treffers, E. E., Li, Y., Tas, A., Sun, Z., van der Meer, Y., de Ru, A. H., Van Veelen, P. A., Atkins, J. F., Snijder, E. J. and Firth, A. E. (2012): Efficient -2 frameshifting by mammalian ribosomes to synthesize an additional arterivirus protein. Proc. Natl Acad. Sci. U. S. A. 109, E2920-E2928. DOI: 10.1073/pnas.1211145109

Firth, A. E., Zevenhoven-Dobbe, J. C., Wills, N. M., Go, Y. Y., Balasuriya, U. B. R., Atkins, J. F., Snijder, E. J. and Posthuma, C. C. (2011): Discovery of a small arterivirus gene that overlaps the GP5 coding sequence and is important for virus production. J. Gen. Virol. 9, 1097-1106.

Hausmann, S., Martin, M., Gauthier, L. and Wucherpfennig, K. W. (1999): Structural features of autoreactive TCR that determine the degree of degeneracy in peptide recognition. J. Immunol. 162, 338-344.

Holtkamp, D. J., Kliebenstein, J. B., Neumann, E., Zimmerman, J. J. and Rollo, H. (2013): Assessment of the economic impact of porcine reproductive and respiratory syndrome virus on United States pork producers. J. Swine Health Prod. 21, 72-84. 
Lemke, C. D., Haynes, J. S., Spaete, R., Adolphson, D., Vorwald, A., Lager, K. and Butler, J. E. (2004): Lymphoid hyperplasia resulting in immune dysregulation is caused by porcine reproductive and respiratory syndrome virus infection in neonatal pigs. J. Immunol. 172, 1916-1925.

Mameli, G., Cossu, D., Cocco, E., Masala, S., Frau, J., Marrosu, M. G. and Sechi, L. A. (2014): Epstein-Barr virus and Mycobacterium avium subsp. paratuberculosis peptides are cross recognized by anti-myelin basic protein antibodies in multiple sclerosis patients. J. Neuroimmunol. 270, 51-55.

Mateu, E. and Diaz, I. (2008): The challenge of PRRS immunology. Vet. J. 177, 345-351.

Meulenberg, J. J. M. (2000): PRRSV, the virus. Vet. Res. 31, 11-21.

Mold, C., Gresham, H. D. and Du Clos, T. W. (2001): Serum amyloid P component and C-reactive protein mediate phagocytosis through murine Fc gamma Rs. J. Immunol. 166, 1200-1205.

Murtaugh, M. P., Stadejek, T., Abrahante, J. E., Lam, T. T. and Leung, F. C. (2010): The everexpanding diversity of porcine reproductive and respiratory syndrome virus. Virus Res. 154, 18-30.

Olasz, F., Bálint, Á., Balka, Gy., Kádár-Hürkecz, E. and Zádori, Z. (2016a): Porcine reproductive and respiratory syndrome virus and the biology of the virus. Literature review [in Hungarian, with English abstract]. Magy. Allatorvosok 138, 523-538.

Olasz, F., Dénes, B., Bálint, Á., Magyar, T., Belák, S. and Zádori, Z. (2016b): Immunological and biochemical characterisation of $7 \mathrm{ap}$, a short protein translated from an alternative frame of ORF7 of PRRSV. Acta Vet. Hung. 64, 273-287.

Ornstein, L. and Davis, B. J. (1964): Disc electrophoresis. I. Background and theory. Ann. N. Y. Acad. Sci. 121, 321-349.

Osorio, F. (2010): PRRSV infections: a world-wide update. Acta Sci. Vet. 38 (Suppl. 1), 269-275.

Quaratino, S., Thorpe, C. J., Travers, P. J. and Londei, M. (1995): Similar antigenic surfaces, rather than sequence homology, dictate T-cell epitope molecular mimicry. Proc. Natl Acad. Sci. U. S. A. 92, 10398-10402.

Routsias, J. G. and Tzioufas, A. G. (2010): B-cell epitopes of the intracellular autoantigens Ro/SSA and $\mathrm{La} / \mathrm{SSB}$ : tools to study the regulation of the autoimmune response. J. Autoimmun. 35, 256-264.

Snijder, E. J. and Meulenberg, J. J. M. (1998): The molecular biology of arteriviruses. J. Gen. Virol. 79, 961-979.

Sospedra, M., Zhao, Y., zur Hausen, H., Muraro, P. A., Hamashin, C., de Villiers, E. M., Pinilla, C. and Martin, R. (2005): Recognition of conserved amino acid motifs of common viruses and its role in autoimmunity. PLoS Pathog. 1, e41. DOI: 10.1371/journal.ppat.0010041.

Stoyanova, V., Tchorbadjieva, M., Deliyska, B., Vasilev, V. and Tsacheva, I. (2012): Biochemical analysis of the epitope specificities of anti-C1q autoantibodies accompanying human lupus nephritis reveals them as a dynamic population in the course of the disease. Immunol. Lett. 148, 69-76.

Vaughan, J. H., Valbracht, J. R., Nguyen, M. D., Handley, H. H., Smith, R. S., Patrick, K. and Rhodes, G. H. (1995): Epstein-Barr virus-induced autoimmune responses. I. Immunoglobulin $\mathrm{M}$ autoantibodies to proteins mimicking and not mimicking Epstein-Barr virus nuclear antigen-1. J. Clin. Invest. 95, 1306-1315.

Vitagliano, L., Fiume, G., Scognamiglio, P. L., Doti, N., Cannavò, R., Puca, A., Pedone, C., Scala, G., Quinto, I. and Marasco, D. (2011): Structural and functional insights into IאB- $\alpha / \mathrm{HIV}-1$ Tat interaction. Biochimie 93, 1592-1600.

Wu, W. H., Fang, Y., Farwell, R., Steffen-Bien, M., Rowland, R. R. R., Christopher-Hennings, J. and Nelson, E. A. (2001): 10-kDa structural protein of porcine reproductive and respiratory syndrome virus encoded by ORF2b. Virol. 287, 183-189.

Wucherpfennig, K. W. and Strominger, J. L. (1995): Molecular mimicry in T cell-mediated autoimmunity: viral peptides activate human $\mathrm{T}$ cell clones specific for myelin basic protein. Cell 80, 695-705. 
You, J. H., Howell, G., Pattnaik, A. K., Osorio, F. A. and Hiscox, J. A. (2008): A model for the dynamic nuclear/nucleolar/cytoplasmic trafficking of the porcine reproductive and respiratory syndrome virus (PRRSV) nucleocapsid protein based on live cell imaging. Virol. 378, 34-47.

Zádori, Z., Szelei, J. and Tijssen, P. (2005): SAT: a late NS protein of porcine parvovirus. J. Virol. 79, 13129-13138.

Zhang, H. and Kono, H. (2012): Economic impacts of porcine reproductive and respiratory syndrome (PRRS) outbreak in Vietnam pig production. Trop. Agric. Res. 2, 152-159. 